\title{
Héroes y antihéroes en el Shabnamé de Ferdousí: una visión mítico-ética
}

\section{Heroes and Antiheroes in the Shabnameb of Ferdowsi: A Mythical-ethical Vision}

\section{SHEKOUFEH MOHAMMADI SHIRMAHALEH*}

Resumen: El Shahnamé de Abol Qasem Ferdousí, un texto poético de la literatura persa del siglo x considerado la épica nacional de Irán, cuenta con fuentes escritas y orales que recogen la tradición poética de diferentes zonas de la meseta iraní; entre ellas, la más importante es el Jodaynamag sasánida (siglo vi e.c.). Como otras épicas, se nutre de mitos, leyendas e historia, y sus protagonistas responden al contexto y las exigencias de las fuentes. Este trabajo busca explicar la construcción de la personalidad de los héroes y los antihéroes del Shahnamé en sus ciclos mítico y heroico, con base en sus funciones míticas y dentro de un marco ético determinado.

Palabras clave: Shahnamé; mitología persa; mazdeísmo; Fereydún; Zahak; Siyawash.

Abstract: The Shabnameh of Abul Qasem Ferdowsi, a poetic text from tenth century Persian literature regarded as the national epic of Iran, has written and oral sources that reflect the poetic tradition of different areas of the Iranian plateau, the most important being the Sasanian Jodaynamag (sixth century c.e.). Like other epics, it derives from myths, legends and history, and the depiction of its protagonists responds to the context and the demands of the sources. This paper seeks to explain the construction of the personality of heroes and antiheroes of the Shahnameh with reference to its mythical and

Recepción: 10 de noviembre de 2015./Aceptación: 16 de febrero de 2016.

* Universidad Nacional Autónoma de México, cielo_sh@yahoo.com 
heroic cycles, based on their functions in traditional myth and the context of different ethical frameworks.

Key words: Shabnameh; Persian Mythology; Zoroastrianism; Fereydun; Zahak; Siyawash.

\section{Introducción}

El Shahnamé de Abol Qasem Ferdousí, la épica nacional de Irán, es una obra que, debido a su estructura, lenguaje y raíces profundas en la cultura persa preislámica, se presta a múltiples interpretaciones en cuanto al tratamiento de sus personajes se refiere. Mientras que una lectura superficial de la obra la reduce a un conjunto de cuentos épicos y fantásticos con fines de enseñanza moral, al profundizar en los relatos nos damos cuenta de que tanto el contenido como la estructura de las leyendas épicas del Shahnamé responden en primer lugar a los objetivos concretos de su fuente escrita más antigua; a saber: el Jodaynamag sasánida. La recopilación de las antiguas leyendas épicas iraníes en forma de un solo libro, el Jodaynamag, sirvió de sustento cultural a un imperio cuyo éxito y cuya gloria estaban muy ligados a la aceptación del clero zoroastriano y, por lo tanto, a su visión ontológica.

Cuando Ferdousí comenzó a escribir su Shahnamé en verso, contaba con numerosas fuentes escritas, mayormente en persa moderno. Merece mencionar que, entre estas fuentes, el Shahnamé de Abu Mansur Tusí1 o el Shahnamé-ye Abumansurí, cuya fuente principal era el Jodaynamag sasánida, era una obra muy conocida, aplaudida durante varias décadas, incluso en los mismos años cuando Ferdousí había comenzado a escribir su Shahnamé, y quizá por ello investigadores como Nöldeke

${ }^{1}$ Abu Mansur Tusí era un militar de alto rango de la ciudad de Tus, la ciudad natal de Ferdousí, quien ordenó y patrocinó la recopilación de un Shahnamé cuya introducción se había conservado durante mucho tiempo como el prefacio del Shahnamé de Ferdousí. Cuatro escritores de origen iraní y conocedores del idioma pahlavi participaron en la recopilación y la redacción del Shabnamé de Abu Mansur, basándose en los textos existentes en persa medio; esta variedad de escritores dio lugar a diferencias de estilo y contradicciones puntuales en las narraciones heroicas. Véase Theodor Nöldeke, Hemaseye meli-e Iran, trad. Bozorg Alavi, Teherán, Negah, 2006, pp. 45-46. 
lo consideran como su fuente principal. Por otra parte, como Omidsalar argumenta, ${ }^{2}$ los Shahnamé posislámicos tenían como fuente tres tipos de textos épicos o legendarios, existentes en persa medio; a saber: libros locales de historia, incluidas leyendas locales - como las historias de Sistán y Tabaristán-, épicas literarias acerca de héroes como Bahram-e Chubín y Garshasp, y una épica nacional que contaba la historia étnica de Irán desde sus comienzos hasta la época sasánida. Nöldeke, a su vez, hace referencia a otras dos obras épicas escritas en persa medio: Yadgar-e Zariran (Memorias de Zarir) y Karname-ye Ardeshir Babakan (Libro de las hazañas de Ardeshir Babakan), y a una tercera más, titulada Pseudokallisthenes ${ }^{3}$ (Pseudo-Calístenes), como fuentes de Ferdousí. De este modo, si nos proponemos determinar de manera exacta las fuentes del Shabnamé de Ferdousí, es preciso considerar como recursos también todos estos textos épicos y legendarios.

Debido a esa diversidad, al proponernos la investigación de los criterios de la formación y el desarrollo de los personajes del Shahnamé, enfocarnos en las características legendarias de los héroes y los villanos del Shahnamé en relación con factores vinculados a la zona de su procedencia se presenta como una posibilidad viable. Sin embargo, el hecho de que la primera recopilación de los mitos y leyendas épicas que conforman el Shabnamé de Ferdousí se haya realizado en la época sasánida es un factor que no podemos dejar de lado. Es necesario comprender a los personajes del Shahnamé también en el marco de la visión mazdeísta y en relación con los fines políticos de la era sasánida que incluyen la recuperación de la gloria pasada mediante la narración de las hazañas de los reyes persas míticos y la creación de vínculos con ellos.

Gracias al trabajo de investigadores como Dumézil ${ }^{4}$ sobre la mitología indoirania, sabemos que muchos de los reyes, príncipes, héroes y heroínas del Shahnaméson personajes

\footnotetext{
${ }^{2}$ Mahmoud Omidsalar, Poetics and Politics of Iran's National Epic, the Shahnameh, Nueva York, Palgrave Macmillan, 2011, pp. 38-39.

${ }^{3}$ Este último, en relación con el pasaje de Alejandro el Macedonio en el Shabnamé. Véase ibid., p. 90.

${ }^{4}$ Véase G. Dumézil, Les dieux Indo-européens, París, Presses Universitaires de France, 1952.
} 
míticos indoiranios, cuyos nombres y descripciones fueron recogidos en el Avesta tras el surgimiento de Zaratustra en Persia. Los himnos Yasht, dedicados principalmente a la evocación de las deidades mazdeístas y la explicación de los rituales relacionados con ellas, incluyen las referencias más detalladas de esos personajes. El Zamyad Yasht (Yasht 19), por ejemplo, menciona a héroes y dinastías míticos prezoroastrianos, como la dinastía Paradata (Pishdadí) y la dinastía Kavi (Kayánida), y reyes como Haoshanha (Hushang), Takhma Urupi (Tahmuras), Yima (Yamshid, que se vuelve a mencionar en Vandidad II), Kavi Vishtaspa (Kay Goshtasp), Kāvi Usan (Kaykavus), Kavi Haosravah (Kayjosrow), etcétera, que constituyen, a su vez, algunos de los protagonistas del Shahnamé. El alcance del mito, sin embargo, va más allá de la mitología del pueblo avéstico y en algunos casos, como en la historia de Zahak y Fereydún y en la historia de Siyawash, descubrimos similitudes con mitos mesopotámicos, como bien han mostrado investigadores como M. Bahar ${ }^{5}$ y B. Beizaí, ${ }^{6}$ y que a su vez exigen otra interpretación.

Por otra parte, los personajes del Shahnamé, tanto sus héroes como sus antihéroes, por lo menos en los dos primeros ciclos del libro, ${ }^{7}$ además presentan y representan características aparentemente adaptadas al fundamento ético del zoroastrismo. Este marco ético comprende una moral trascendental y una moral práctica, ambas adoptadas por el Shahnamé, aun en diferentes niveles. De esta manera, los héroes y los villanos del Shabnamé responden a un pensamiento dual que distingue, por un lado, las fuerzas de la luz y, por otro, las de la oscuridad, y

${ }^{5}$ Mehrdad Bahar, Pajuheshi dar asātire irān (Investigaciones acerca de los mitos de Irán), Teherán, Agah, 2014.

${ }^{6}$ Bahram Beizaí, Hezar afsan kojast? (¿Dónde está Los mil cuentos?), Teherán, Roshangarán, 2011.

${ }^{7}$ Los estudiosos del Shahnamé tienen consenso en aceptar la división sugerida por A. E. Bertels, que distingue tres ciclos principales en la obra: el ciclo mítico, el ciclo heroico y el ciclo histórico, en orden de aparición. El ciclo mítico comienza con el mito de la creación y narra las historias de los primeros hombres-reyes; el ciclo heroico, el más extenso de todos, se plantea como la continuación del ciclo anterior e incluye tanto a los reyes y los príncipes míticos como a héroes y heroínas fantásticos. El ciclo histórico cuenta historias acerca de los reyes sasánidas y también es presentado como la continuación de los otros dos ciclos para terminar con la conquista árabe de Persia. 
se convierten así en la personificación de los atributos de estas dos fuerzas.

Otro elemento determinante para el desenvolvimiento de los personajes del Shahnamé parece ser la ontología zurvanistaislámica, que además de aparecer junto con la ética zoroastriana ${ }^{8}$ en los aspectos prácticos y de manifestarse en las palabras y las decisiones de los personajes, se traduce en la presencia de un destino especialmente cruel, cuyo poder sobrepasa el libre albedrío del héroe.

En este trabajo, intentaré confirmar los criterios más importantes que influyen en el desarrollo de los personajes del Shabnamé de Ferdousí, independientemente de la diversidad de sus fuentes, y analizaré algunos de los personajes de la obra en el marco de estos criterios. Parto de la idea de que dichos criterios son principalmente funciones míticas en relación no sólo con las figuras mitológicas, sino también con el mito de creación mazdeísta y sus características épicas, éticas y míticas; además, tendré en cuenta otro criterio que pretendo identificar como la ética zurvanista-islámica. Los personajes elegidos para el análisis son aquellos que debido a la antigüedad de sus precedentes resultan más ilustrativos en relación con nuestra visión mitológica y que además han trascendido y se han convertido en personajes simbólicos durante la historia más reciente de Irán.

Por lo tanto, comenzaré con algunas aclaraciones acerca del pensamiento mazdeísta que nos aportarán la base ética y mítica. A continuación, estudiaré dos visiones clave arraigadas en el zurvanismo y el islam (perspectivas de vida y muerte) para llegar a otros dos conceptos, pertenecientes a las creencias religiosas

${ }^{8} \mathrm{La}$ ética zoroastriana-mazdeísta define las virtudes y los buenos actos como aquellos que Mazda ha ordenado, y describe los vicios y lo prohibido como aquellos actos realizados e inducidos por Ahrimán. El Dinkerd nos dice además que la mejor actitud o la más correcta éticamente es aquella que observa el equilibrio y no se inclina hacia ningún extremo; tal actitud puede lograrse a través del conocimiento sabio y su consecuencia es obtener siempre buenos resultados y finales. Entre las virtudes más destacadas, surgidas de la sabiduría, están la generosidad hacia los buenos seres humanos y buscar siempre la paz y la amistad con ellos, la justicia, el respeto, la sinceridad, etcétera. En el lado contrario, los peores vicios son la enemistad y el egoísmo, la injusticia, la avaricia y la mentira. La visión zurvanista se adapta a esta visión y la islámica propone lo mismo, con la diferencia de que ambos hablan de un dios creador único que lo decide y controla todo. 
populares; a saber; el destino y el buen nombre, y finalizaré con un pequeño estudio de los nombres de los personajes del Shahnamé, como la confirmación de nuestra visión ético-épica de ellos.

\section{Mitología épico-ética}

La esencia del pensamiento preislámico en Irán es la dualidad del bien y el mal, representada, respectivamente, por Ahura Mazda (Sepandar Minú), el creador del bien y el soberano del reino de la luz, y Ahrimán (Angra Minú), el creador del mal y el soberano del reino de la oscuridad. ${ }^{9}$ Según el mito de creación mazdeísta, la pareja dual, preexistente y eterna, coexistía pacíficamente hasta que Ahrimán, movido por la avaricia, decidió agredir el reino de la luz; la consecuencia de esta agresión fue la creación del mundo material (Guitî́) ${ }^{10}$ por Mazda con el fin de que las creaciones materiales lo apoyaran en su batalla contra Ahrimán: Ahura Mazda no es un dios todopoderoso, pero podrá convertirse en uno cuando haya vencido a Ahrimán.

Este pensamiento ha penetrado en los mitos persas y les ha otorgado un fundamento ético, ya que la ética es la consecuencia inevitable de distinguir la dualidad del bien y el mal, cuya diferencia se manifiesta tanto en la conciencia, la mente y el pensamiento como físicamente. Shahroj Meskub, uno de los investigadores más visionarios de las antiguas culturas de Persia, opina que en la cosmovisión avéstica, la ética es un fenómeno ontológico, "en el sentido de que sus principios y valores son el resultado inevitable de la comprensión de la existencia, la aparición y el funcionamiento de los dos mundos únicos MinúGuití [mundo del espíritu y mundo material]". ${ }^{11}$ Así, los prin-

${ }^{9}$ El Avesta además establece otra dualidad entre ashe, la verdad y la justicia, cuya representación física es el fuego, y doruy, la mentira y la injusticia, que se manifiesta físicamente en los demonios. A lo largo de todo el Avesta, especialmente en los Gathas, encontramos referencias a la lucha entre Ashe y Doruy; véase, por ejemplo: Avesta, 2 vols., ed. de Yalil Dustjah, Teherán, Morvarid, 1991: Yasne: 8:30, 2:31, 14:44, 3:49 y Yasht 12:19.

${ }^{10}$ Antes de la creación del mundo material, Ahura Mazda había creado el mundo de los espíritus arquetípicos (Minú): véase ibid., vol. II, pp. 934-936 y 1069.

${ }^{11}$ Shahroj Meskub, "Ta.amoli dar akhlagh: az avesta be Shahnamé" (Reflexiones sobre ética, del Avesta al Shahnamê), Irannameh, núm. 64, 1999, p. 583. 
cipios éticos preislámicos no provienen de un solo dios, sino que están presentes en la naturaleza de la creación.

Dicha dualidad, por otra parte, exige necesariamente un enfrentamiento, ya que ninguna de las dos fuerzas puede aceptar o tolerar a la otra, y más bien debe intentar destruirla. En palabras de S. Meskub: "Si Ahura Mazda acepta a Ahrimán, o incluso lo abandona a su suerte, ya no puede ser la luz y la bondad absoluta y se convierte en su cómplice, y viceversa". ${ }^{12}$ De este modo, la mitología persa es además necesariamente épica, y sus héroes y sus antihéroes actúan en el marco de esta épica ética. El pensamiento preislámico, además, le otorga un lugar de privilegio a los seres humanos como cómplices y ayudantes de Mazda en la creación: el faravahar, el quinto y el más poderoso elemento componente de los seres humanos, junto con el cuerpo, la mente, el espíritu y el espejo, es la fuerza gracias a la cual la creación de Mazda se vuelve viva y se pone en movimiento; ${ }^{13}$ el faravahar, además, goza de absoluta libertad para elegir de qué lado luchar en la guerra entre el bien y el mal, ${ }^{14}$ lo cual acentúa el concepto de que los seres humanos son responsables de sus actos. De este modo, decimos con Meskub, "cualquier acto éticamente correcto traspasa el pequeño círculo de la vida individual y afecta a todo el mundo [...] así el hombre no es responsable sólo de sus actos, sino también del destino del mundo". ${ }^{15}$

Los reyes y los héroes del Shabnamé nacen y se desarrollan según esta predefinición mítico-épico-ética y su sentido de justicia e injusticia, sabiduría e ignorancia, veracidad o falsedad, etcétera, se basa en estos mismos principios. Por otra parte, debido a la visión nacionalista-religiosa que se refleja en el Shahnamé de Ferdousí a través de sus fuentes sasánidas, la tierra de Irán se establece en la obra como la morada del bien, como un territorio cuyos reyes y héroes luchan por el predominio del bien y a favor de Ahura Mazda ${ }^{16} \mathrm{y}$, por lo tanto, gozan de la

${ }^{12}$ Ibid., p. 582.

${ }_{13}$ Avesta, op. cit., Farvardin Yasht.

${ }_{14}$ Bondahesh, ed. de Mehrdad Bahar, Teherán, Tus, 2012, p. 48.

${ }^{15}$ Meskub, "Ta.amoli dar akhlagh: az avesta be Shabnamé", op. cit., p. 584.

${ }^{16}$ Tras la división tríadica del mundo entre los hijos de Fereydún, Turán se presenta como el territorio del mal y la oscuridad, y forma junto con Irán la dua- 
gloria divina, o Farr-e izadí. De este modo, el primer rey poseedor de la gloria divina en el Shabnamé, Yamshid (Yima en la mitología indoirania), también es el primero nombrado como el rey de Irán; de hecho, es igualmente con Yamshid cuando se pone de manifiesto, por primera vez, el disturbio de la paz y el equilibrio del mundo causado por la oscuridad. Yamshid es un rey adornado con todas las virtudes imaginables, como si fuera Ahura Mazda mismo, y bajo su reinado el mundo se civiliza y todas las criaturas viven pacíficamente sin conocer ni la enfermedad ni la muerte, como si del primer ciclo de la vida del mundo ${ }^{17}$ o del reinado absoluto de Ahura Mazda se tratase; el mundo de Yamshid es tan perfecto que finalmente un día olvida que su poder le fue concedido por Mazda y se proclama el único creador del mundo. El Avesta habla de doruy (la mentira) como la causa de esta falsa proclamación, y el Shabnamé culpa a la avaricia (az). Curiosamente, tanto Az como Doruy están entre los demonios principales en el pensamiento mazdeísta, así que Yamshid es agredido por estos demonios, igual que el reino de la luz es agredido por Ahrimán; el significado del nombre de Yamshid (Yamah Xšaitah: gemelo radiante) y los atributos solares que acompañan su figura en los textos zoroastrianos ${ }^{18}$ afirman su función como el representante de Mazda y rey del reino de la luz. La falsa proclamación de Yamshid lo condena a ser abandonado por su pueblo una vez que la gloria divina también lo ha abandonado; finalmente, el gran rey solar es derrotado y asesinado por el villano más oscuro de todo el Shahnamé: Zahak. Las descripciones del reinado de Zahak en el Shahnamé, en el que la oscuridad, la magia negra y la muerte son omnipresentes, trazan a Zahak como la contraparte perfecta de Yamshid, y, por lo tanto, como Ahrimán, el polo opuesto de Mazda y soberano del reino de la oscuridad. De este modo, se

lidad bien-mal. Esta dualidad y su constante lucha se refleja en la enemistad de estos dos territorios, y sus reyes y héroes, a lo largo de todo el ciclo heroico del Shahnamé.

${ }^{17}$ Según el mito de creación zurvanista, la duración total de la vida del mundo es de nueve mil años, divididos en tres ciclos de tres mil; en el primer ciclo, Ahura Mazda es el rey predominante; en el segundo gobierna Ahrimán, y en el tercero se desencadena la guerra entre ambos.

${ }^{18}$ Véase, por ejemplo: Avesta, op. cit., Yasht 19, Vendidad 2, Hat 9. 
crea un paralelismo entre los personajes de Yamshid y Zahak y la pareja dual de Ahura Mazda y Ahrimán en cuanto a sus características, su función en el mundo y el comienzo de su enfrentamiento a causa de la agresión del mal. Estos dos reyes en el Shahnamé responden a esta visión mítico-épica y sus personajes se desarrollan en el marco de esta misma visión. El contraste extremo entre estos dos personajes, como dos polos opuestos, es un caso único en el Shabnamé en cuanto a su fuerza: la contraposición de los personajes de Zahak y Fereydún, o Kayjosrow y Afrasyab, es también definida con mucha claridad pero no alcanza dimensiones semejantes. Así, pues, el tratamiento humanístico que reciben casi todos los héroes y los antihéroes del Shabnamé se les niega a los dos primeros reyes, Yamshid y Zahak, debido a la preeminencia de sus características mitológicas.

El personaje de Zahak, además, responde a una antigua creencia mitológica indoirania en la que, cada año, el dragón de la sequía domina el mundo por cierto periodo, pues secuestra a las dos deidades de las aguas, la fertilidad y la perfección, y es finalmente vencido por otro dragón, el de la fecundidad, quien libera a las deidades encerradas y renueva el mundo. ${ }^{19}$ Desde esta perspectiva es interesante observar que en el Shabnamé, Zahak hace suyas a las dos hermanas de Yamshid, Arnavaz y Shahrnaz, quienes son liberadas tras mil años por el rey Fereydún, que derroca a Zahak y lo encierra en el monte Damavand. Fereydún, ${ }^{20}$ igual que Zahak, es un dragón de tres cabezas -así se presenta a sus tres hijos para ponerlos a prueba- y su figura está vinculada con la lluvia y la fertilidad, tanto en el Shabnamé como en el Avesta. Asimismo, por un lado, el hecho de que Fereydún reciba del ángel Sorush la orden de no matar a Zahak y encerrarlo hasta que llegue su día, alude a la repetición de los ciclos míticos de vida-muerte, que coinciden con la muerte y el renacimiento de la naturaleza al eliminar la posibilidad de la destrucción total de Zahak; y, por el otro, el señalamiento de que Zahak será destruido completamente

${ }^{19}$ Véase Beizaí, Hezar afsan kojast?, op. cit.

${ }^{20}$ Para un detallado análisis mitológico del personaje de Fereydún, véase Shahroj Meskub, Chand goftar dar farhangue irán (Algunas palabras acerca de la cultura iraní), Teherán, Zenderud, 1992, pp. 25-82. 
cuando llegue su día, plasma la ontología mazdeísta, en la que el periodo de la existencia del mal es limitado, calculado y definido, y la promesa escatológica de un apocalipsis y la llegada de un salvador definitivo garantizan la aniquilación total del mal y el establecimiento del reino del bien hasta el infinito. ${ }^{21}$ Este salvador mesiánico aparece en el Shahnamé como Kayjosrow, hijo de Siyawash, quien consigue matar a Afrasyab, el rey de Turán, y restablecer la paz y la justicia por varios siglos. Así, pues, tras una larga historia de batallas, el ciclo heroico del Shabnamé concluye con la desaparición de Kayjosrow en las faldas del monte Damavand, ${ }^{22}$ suceso que responde a la creencia mazdeísta de que el salvador definitivo es inmortal y tras haber cumplido su misión volverá a morar con Mazda en el cielo.

Como podemos observar, los personajes principales del ciclo mítico del Shahnamé, que termina con el fin del reinado de Fereydún, conservan un fundamento mitológico que sostiene una estrecha relación tanto con los mitos de creación preislámicos como con los antiguos mitos indoiranios, en los que los reyes son representaciones de las fuerzas de la naturaleza y las clases sociales; así, sus características y sus funciones míticas destacan por encima de su condición de humanos mortales. A partir del ciclo heroico, sin embargo, son los héroes, y no tanto los reyes (a excepción de Kayjosrow), quienes adquieren protagonismo, y sus personajes se desarrollan con gran humanismo y sin polarizaciones, aunque sus hazañas se desenvuelven en contextos todavía míticos y mágicos.

${ }^{21}$ Cabe mencionar que la historia de Zahak y Fereydún además tiene dimensiones étnicas y nacionalistas que están fuera del marco de este trabajo. Aquí basta decir que Ferdousí desarrolla el personaje de Zahak de tal manera que sus características étnicas, como rey árabe, se enlazan con sus rasgos míticos y (anti)éticos para presentar la figura prototípica de los conquistadores árabes de Persia desde una perspectiva claramente nacionalista.

${ }^{22}$ Según el Avesta (op. cit., Yasht 19:1) y otros textos zoroastrianos (Bondahesh, op. cit., p. 71), el monte Damavand, alternativamente llamado Alborz, es la primera montaña del mundo y la fuente de luz y agua, que había tardado 800 años en crecer, con sus raíces profundamente sumergidas en la tierra y su pico atado al cielo; el cuerpo de esta montaña marcaba la morada de las estrellas, la Luna, el Sol y la luz infinita. De allí que esta montaña se presenta en el Shahnamé como un lugar mágico donde se conectan dos mundos, el del espíritu, habitado por Ahura Mazda, y el de la materia, habitado por los humanos. 


\section{Visiones de vida y muerte}

Los personajes del ciclo heroico del Shahnamé, al tiempo de ser legendarios, poseer habilidades sobrenaturales y actuar en la dirección de una misión mítico-épica (apoyar al bien en su batalla contra el mal), muestran características puramente humanas: son una combinación de buenos y malos atributos ${ }^{23}$ que a veces los conduce a tomar decisiones incorrectas o a actuar indebidamente, y otras veces los ayuda a realizar los más heroicos, valientes y bondadosos de los actos: son a veces justos y a veces injustos, bondadosos y crueles en diferentes casos, sabios e inconscientes alternativamente, a veces de una fe firme y otras veces dudosos. Estos personajes evolucionan según dos puntos de vista principales que abarcan la vida y la muerte, y se adhieren a dos creencias fundamentales, una derivada de los pensamientos zurvánicos e islámicos, creer en el destino, y otra, de la importancia del buen nombre, arraigada en la cultura popular.

La perspectiva de los personajes del Shabnamé respecto a la vida está marcada por dos realidades: la libertad y el destino; ${ }^{24}$ la libertad de pensar, tomar decisiones y determinar los propios actos está condicionada por el poder del destino, como la más soberana y la más incomprensible de las fuerzas. Los protagonistas del Shabnamé están armados con valentía, como poco, y no le temen a la muerte, pero saben que para todos ellos se ha predeterminado un inevitable destino que desconocen y no pueden comprender. Así, en sus palabras, y en palabras de Ferdousí como narrador, se observa claramente la expresión de esta contrariedad de matices más bien zurvanistas e islámicos: ${ }^{25}$

${ }^{23}$ Los príncipes Iray y Siyawash son excepciones en este sentido, ya que se les asignan atributos únicamente positivos, aquellos que respaldan su papel como símbolos del bien.

${ }^{24}$ Véase también: Mohammad Ali Eslami Nadushan, Zendegui va Marg-e Pablevanan dar Shahnamé (La vida y la muerte de los héroes en el Shabnamee), Teherán, Sahami Enteshar, 2012, pp. 87-109.

${ }^{25}$ Creer en el destino, como fuerza suprema, está relacionado con las cosmovisiones que conciben dioses únicos, ya que la fuerza del destino, o la suerte o la fortuna, es en realidad la representación más perceptible de la voluntad del dios único cuya omnipotencia y soberanía le conceden la cualidad indispensable de determinar el curso de los sucesos. La visión dual de la cultura preislámica no posee estas características. 
"Así ha sido desde siempre y no es novedad ninguna, la vanidad del mundo es desmesurada: a algunos sube hasta el alto cielo, a otros rebaja hasta lo más indigno, sin tener lazos de amistad con los primeros ni rencor contra los segundos; ¿quién sabe los secretos del creador del mundo?". ${ }^{26}$

Tal contraste tiene como consecuencia una visión del universo como un lugar de paso, atrapado en lo finito del tiempo de vida de cada ser; los héroes del Shahnamé, conscientes de su condición de mortales restringidos por fuerzas que los sobrepasan, eligen disfrutar la vida, al tiempo de aprovecharla para su misión: "Un día en la altura y un día abajo, a veces triste, a veces jubiloso; es mejor, pues, que pasemos los días con una copa capaz de iluminar el mundo". ${ }^{7}$

Así, las escenas de celebraciones y festines, previas o posteriores a las batallas o a la toma de grandes decisiones, abundan en los pasajes del Shahnamé, y el vino y la risa alcanzan la posición de las cosas esencialmente necesarias. Del mismo modo, las tres características primordiales de los grandes reyes y héroes incluyen, además de la valentía y la sabiduría - que a su vez se traducen en otros valores y abarcan todas las demás virtudes-, el arte de saber gozar la vida.

La misión principal de los héroes del Shabnamé responde a los principios éticos anteriormente mencionados, pero al mismo tiempo se vincula con otra secundaria: alcanzar un buen nombre y conservarlo hasta la muerte. ${ }^{28}$ Adquirir el buen nombre (Nam-e nik) o la buena fama depende de la rectitud, la justicia y la sabiduría del héroe, así como de su valentía y sus éxitos en su misión ética de apoyar el bien, representado por los reyes persas. De esta manera, las decisiones de los héroes se sopesan y se miden en términos de las influencias que tendrían sobre su buen nombre. La importancia de dejar buenos recuerdos en este mundo, al morir, también se refleja en el carácter hereditario del buen nombre, como un bien valioso del que los hijos pueden gozar o estar privados. Este concepto,

${ }^{26}$ Abol Qasem Ferdousí, Shahnamé, ed. de B. E. Edvardovich, Teherán, Qoqnus, 2014, p. 593, versos 604-606. La traducción es mía.

${ }_{27}$ Ibid., p. 170, versos 1630-1631. La traducción es mía.

${ }^{28}$ Véase Shahroj Meskub, Armaqane mur: jostari dar Shahnamé (Aportación de hormiga: pequeña investigación del Shabnamee), Teherán, Ney, 2004, pp. 41-61. 
perteneciente al segundo ciclo del Shahnamé, comprende no sólo a los héroes iraníes, sino también a los no iraníes, siempre y cuando destaquen por su rectitud, valentía y sabiduría, como es el caso de Pirán, el héroe principal de Turán y consejero del rey Afrasyab. De igual manera, no todos los reyes y héroes iraníes son impecables y de buena fama; el caso del rey Kaykawus es especialmente interesante, ya que manifiesta claramente un carácter dual que a veces lo guía hacia el bien y otras veces hacia el mal, y por ser, indirectamente, el causante de la muerte de uno de los príncipes más puros e inocentes de todo el Shabnamé: Siyawash.

Por otro lado, la muerte también es un elemento ubicuo en el Shahnamé y sus héroes y reyes toman consciencia de ella como algo natural e inevitable, capaz de convertirse en una misión con efectos esenciales en la vida de los demás individuos y en la vida del universo en general. La mayoría de los héroes del Shahnamé no sólo enfrenta la muerte en cada batalla sino que, en ocasiones, la reta o va en busca de ella para lograr un fin trascendente, como es el caso de Rostam - perseverante en su obligación de proteger Irán-y Esfandyar - plenamente dedicado al establecimiento total del mazdeísmo-: ¿qué importa la muerte de un héroe si el destino del mundo mejora a causa de ello?

Pero existen también otros héroes que asumen la muerte como su función principal, la razón de su vida, como los príncipes Iray y Siyawash. Ellos invitan a la muerte a la propia morada y la reciben con calma y con los brazos abiertos: Iray acude al encuentro de sus dos hermanos que han expresado explícitamente sus intenciones de matarlo, y Siyawash repite la misma acción con Afrasyab y Garsiwaz y su numeroso ejército. Ambos héroes son símbolos de sabiduría, pureza e inocencia, y ambos juegan, en diferentes puntos, un papel importante en la reestructuración de los valores morales del pueblo iraní y la definición enfática de los conceptos duales de justiciainjusticia. ${ }^{29}$ La muerte de Iray rompe el equilibrio del reinado perfecto de su padre, Fereydún, y de ella nace el concepto de injusticia (bidad): sólo el hecho de vengar la sangre inocente

${ }^{29}$ A su vez relacionada con la dualidad bien-mal, luz-oscuridad, verdad-falsedad. 
puede volver a establecer el equilibrio de la justicia (dad). En el caso de Siyawash ocurre exactamente lo mismo, con la diferencia de que éste es además el protector de la justicia por excelencia: elige el destierro voluntario cuando su padre, Kaykawus, le pide no respetar el pacto de paz con el enemigo, ya que lo considera injusto, y muere a manos del mismo enemigo a quien había pedido asilo.

Por otro lado, la muerte del "otro" no siempre aparece en el Shahnamé como la muerte ajena, la del enemigo, sino que anida también en el seno de las familias. En el caso de los héroes, son recurrentes el asesinato de un hermano por otro hermano (los hermanos de Fereydún intentan matarlo; los dos hijos mayores de Fereydún matan a su hermano menor) y el asesinato de un hijo por su padre (Rostam mata a Sohrab; Fereydún ordena el asesinato de Salm y Tur); en el caso de los antihéroes, sin embargo, estamos frente al asesinato del padre a manos de su hijo: Zahak, por ejemplo, mata a su padre, Mardas, para arrebatarle su reino. Algunos investigadores han interpretado estas muertes basados en la concepción de las sociedades patriarcales, donde los padres simbolizan los valores principales y establecidos y su muerte tendría connotaciones éticas; es decir, significaría la muerte de los principios; de allí que el villano mate a su padre y el héroe, a su hijo. ${ }^{30}$ Sin embargo, existe una posibilidad interpretativa más profunda basada en el humanismo persa de la época en que se escribe el Shahnamé, una visión que plantea la pregunta de por qué el ser humano, a diferencia de otros animales, es capaz de matar a los miembros de su propia familia o de no reconocer a su propio hijo (en el caso de Rostam y Sohrab). Este comportamiento humano antinatural puede comprenderse en el marco ético de la obra, donde el ego y vicios como la envidia, la ira, la mentira, la avaricia, que marcan la perdición o la muerte de los héroes, son demonios por vencer y obstáculos por superar.

Los antihéroes del Shabnamé, a su vez, están presentados como mensajeros y ejecutores de la muerte; a lo largo de todo el libro, sólo dos antihéroes juegan papeles principales: Zahak

30 Véase Dick Davis, Epic and Sedition: A Case of Ferdorwi's Shabnamé, Odenton, Mage Publishers, 2006. 
en el ciclo mítico y Afrasyab en el ciclo heroico. B. Sarkaratí, en su artículo "El fundamento mítico de la épica nacional de Irán" ${ }^{31}$ traza un paralelismo entre la duración de los primeros dos ciclos de Shahnamé, sus héroes, reyes y antihéroes, con la concepción mítica de la duración del mundo y la presencia-ausencia-coexistencia del bien y el mal en cada periodo. De esta manera, Afrasyab, igual que Zahak, es representante de Ahrimán, y su relación con la muerte, la destrucción y la sequía se debe a lo mismo. Sin embargo, además de tener una función mítica, Afrasyab es un personaje muy humano, cuyos rasgos de villano no están tan polarizados como en Zahak. Afrasyab es el rey de Turán, el territorio enemigo de Irán, está mayormente dominado por la ira y es poco sabio; pero al mismo tiempo es capaz de amar y proteger a un príncipe iraní desterrado, Siyawash, aunque finalmente lo mate engañado por su propio hermano.

\section{Pruebas y obstáculos}

Otro elemento significativo en la vida de los héroes del Shahnamé es la existencia de obstáculos y pruebas que, al tiempo de suponer experiencias cercanas a la muerte, simbolizan los límites del propio ser de los héroes: pasar una prueba o superar un obstáculo significa el ascenso del héroe ${ }^{32}$ de un nivel a otro, física y espiritualmente. ${ }^{33}$ Son representativas la prueba de agua que ha de pasar Fereydún para llegar al palacio de Zahak, la prueba de fuego de Siyawash y las siete labores de Rostam. En el primer caso, Fereydún llega con su ejército a las orillas de Arvand Rud (Shatt al-Arab); el guardián del río les niega el paso en embarcaciones ya que carecen de la autorización de Zahak, y el héroe decide cruzar el caudaloso y agitado río montado en su caballo. Superar esta prueba significa para Fereydún su

${ }^{31}$ Bahmán Sarkaratí, "Bonyane asatirie hemaseye mellie iran” (El fundamento mítico de la épica nacional de Irán), Revista de la Facultad de Literatura y Humanidades de la Universidad de Tabriz, núm. 125, 1979, pp. 1-61.

${ }^{32}$ Esta oportunidad no se presenta a los antihéroes, a pesar del tratamiento humanístico de sus personajes.

${ }^{33}$ Meskub, Chand goftar dar farhangue irán, op. cit., p. 49. 
ascenso del nivel de joven héroe al nivel de un rey merecedor de la corona de Irán y, mitológicamente hablando, su paso de la sequía a la fecundidad; aquí la relación del personaje mítico de Fereydún con el agua - como dragón de fertilidad- es llamativa: el obstáculo por superar tiene la misma esencia que el propio héroe, y así Fereydún no cruza un río, sino los límites de su propia existencia.

Es muy parecido el caso de la prueba de fuego presentada a Siyawash. La madrastra de Siyawash lo acusa de haber intentado seducirla y los sabios de la corte de Kaykawus le aconsejan al rey que antes de llevar a cabo la decisión de matar a su hijo, lo ponga a prueba y le pida pasar por el fuego. Un llameante fuego se enciende y Siyawash pasa a través de él, montado en su negro caballo, y sale ileso, con lo que prueba su inocencia y su pureza. La concepción del fuego como la creación más sagrada de Ahura Mazda es uno de los principios de la religión mazdeísta, y Siyawash es el personaje más sagrado de todo el Shahnamé, debido a su sabiduría y su pureza, dos de los atributos más destacados del creador del bien. Así, pues, el héroe de nuevo sobrepasa los límites de su propio ser y reconfirma su esencia, presentándose como un príncipe puro merecedor del reino de su padre (el reino de Irán: reino del bien).

En cuanto al héroe Rostam, las siete labores consisten en siete enfrentamientos con animales feroces, criaturas mágicas y duras condiciones climáticas, y representan siete niveles de preparación para una batalla final; a saber: la confrontación con el temible y feroz demonio blanco (Div-e Sepid), quien ha apresado al ejército de Irán. Teniendo en cuenta la adjudicación, en el mazdeísmo, de características demoniacas tanto a los animales feroces como a los practicantes de la magia (negra), se confirma la idea de que las siete labores de Rostam representan sus etapas de iniciación en la lucha contra pequeños demonios, con el fin de estar preparado para la batalla contra un demonio mayor. Al mismo tiempo, cada una de las siete labores supone un reto al héroe, pues lo ponen a prueba a veces física y a veces espiritualmente. De este modo, Rostam también se supera a sí mismo al vencer cada obstáculo, y la lucha contra los demonios externos se traduce en la lucha contra sus propias flaquezas. 


\section{Nombres y connotaciones}

Los nombres de los personajes del Shahnamé en los dos primeros ciclos de la obra ${ }^{34}$ están fundamentados en la mitología indoirania y su significado etimológico puede descifrarse con base en el persa medio o pahlavi y el avéstico principalmente. Cada nombre describe los atributos más llamativos del personaje a quien denomina, ora en términos de su función mitológica, ora en relación con sus rasgos físicos y psíquicos. De esta manera, por ejemplo, los nombres de Yamshid (Yamah Xšaitah: gemelo radiante) y Fereydún (Thraetaona: el tercero) indican su posición y su función dentro de una jerarquía de deidades míticas, mientras que los nombres de Zahak (Aži Dahāka: serpiente humanoide) y Rostam (Roadha Taxma: robusto y fuerte) los describen físicamente; el de Afrasyab (Franrasyan: terrorífico) lo describe psíquicamente; el del primer hombre, Kayumars (Gayō Marətan: vida mortal), describe la esencia de su ser, y el de Siyawash (Syāvaršan: de caballo negro) indica su relación con el tótem de caballo al tiempo de referirse a su bien más apreciado, su caballo negro (Shabrang: del color de la noche). ${ }^{35}$

Este criterio de asignación de nombres en el Shahnamé, además, se pone de manifiesto en la ausencia de nombres propios en el caso de algunos de los personajes. El más llamativo es el caso de los tres hijos de Fereydún y sus respectivas esposas: ${ }^{36}$ una vez que los hijos del rey Fereydún han llegado a una edad adecuada, su padre le pide a su mejor consejero viajar alrededor del mundo en busca de tres princesas, del mismo padre y la misma madre, vírgenes y sin nombres como sus hijos, y dignas de casarse con ellos. La narración continúa con el encuentro de los hijos de Fereydún con las princesas, la petición de su mano, el desciframiento de un enigma por los príncipes, la anu-

${ }^{34}$ El tercer ciclo del Shahnamé conserva los nombres verdaderos de los personajes históricos; por lo tanto, lo hemos excluido de este análisis.

${ }_{35}$ Para las discusiones acerca de los nombres mencionados, véanse, por ejemplo, Shirzad Aghaee, Nam-e kasan va ja'i-ha dar Shahnama-ye Ferdousi (Personajes y lugares en el Shabnamé de Ferdousí), Nyköping, Behrang, 1993; Bruce Lincoln, Priests, Warriors and Cattle, Berkeley-Los Ángeles, California University Press, 1981; y Émile Benveniste, Titres et noms propres en Iran ancien, París, C. Klincksieck, 1966.

${ }^{36}$ Ferdousí, Shahnamé, op. cit., pp. 54-55, sección 6. 
lación de un hechizo y, finalmente, su partida hacia Irán con sus respectivas novias, sin que todavía los príncipes hayan sido llamados por sus nombres. En este punto, Fereydún, con el objetivo de poner a sus hijos a prueba y conocer su esencia, se transforma en un dragón de tres cabezas y se aparece ante ellos en su camino. Cada hijo reacciona de manera diferente ante el dragón y, acto seguido, Fereydún vuelve a tomar su forma humana, les explica lo sucedido y le otorga un nombre a cada uno de ellos y a sus respectivas esposas: al hijo mayor, quien decide evadir al dragón y no enfrentarse a él, lo denomina Salm; al mediano, quien no duda en desvainar su espada y atacar al dragón, lo llama Tur, y al menor, quien le advierte al dragón que si no los deja en paz lo matará, lo nombra Iray.

El primer nombre, Sairama en avéstico, se refiere al pueblo ario de los sármatos, habitantes del oeste de la meseta iraní, y significa "veterano" y "sabio"; la palabra Salm, además, se acerca fonéticamente a la raíz árabe de "سـلم", que significa "tranquilidad, paz". El segundo nombre, forma abreviada del avéstico Tūrya, se refiere a los habitantes del este y noroeste de la meseta iraní, viejos enemigos del pueblo avéstico, y significa "valiente". Por último, Iray, Airiya en avéstico, Ėric en pahlavi, se refiere al pueblo ario, habitantes principales de la meseta iraní, y significa "noble". Como podemos observar, los nombres de los hijos de Fereydún corresponden a su personalidad definida a través de una prueba; los nombres además explican la manera en que Fereydún divide posteriormente los territorios del mundo entre sus hijos: nombra a Salm, rey de Rum y el Occidente (Asia Menor); a Tur, rey de Turán y el Oriente (Asia Central hasta China), y a Iray, rey de Irán y Arabia. Las esposas reciben también nombres según sus características físicas: Arezú (anhelo), Mah (luna) y Sahí (esbelta).

\section{Conclusiones}

Como se pudo observar, los personajes del Shahnamé de Ferdousí, en los primeros dos ciclos de la obra, están ligados a la mitología y las leyendas no sólo preislámicas sino también premazdeístas de diferentes zonas del imperio persa, y conservan, en gran medida, sus características míticas y legendarias, que 
se reflejan en su papel dentro de la obra, en su modo de vivir y morir y en sus nombres. La diversidad de su procedencia invita a una interpretación de los personajes en los diferentes contextos geográficos, históricos y sociales que incumben a cada leyenda; sin embargo, la indudable naturaleza ética de estos mitos y leyendas que define a los héroes y los antihéroes como la personificación del bien y el mal, ora polarizados, ora combinados, se adapta claramente, como se ha podido mostrar, a la visión mazdeísta predominante en la época sasánida. El hecho de que este conjunto de mitos y leyendas se haya unificado en un marco mazdeísta-zurvanista-islámico dentro del Shabnamé de Ferdousí exige un acercamiento a los personajes que parta de las implicaciones de dicho marco.

La convivencia de la mitología prezoroastriana y la ética mazdeísta se manifiesta claramente en los héroes y los villanos del ciclo mítico, que destacan por sus dimensiones y funciones míticas y al mismo tiempo ejemplifican la dualidad básica de la ontología mazdeísta. Por otro lado, los héroes y los villanos del ciclo heroico sobresalen por sus atributos humanos y sus personalidades menos polarizadas, mientras que la ética trascendental de los mitos de la creación preislámicos marca las decisiones y los actos de los reyes (buenos y malos) y la misión de los héroes, y se transforma en una moral práctica. Es por ello que los nombres de los protagonistas del Shabnamé están lejos de la arbitrariedad y los definen física y psíquicamente en el marco de sus funciones y sus papeles en la obra.

Además, el tratamiento humanístico de los personajes, especialmente en el ciclo heroico, está ligado a creencias zurvanistas e islámicas no propiamente religiosas, que se manifiestan en el comportamiento social e individual de los héroes y en su modo de percibir el mundo, sin influir en la naturaleza y el objetivo de su lucha: son conscientes del papel que juegan en el destino del mundo, pero al mismo tiempo son seres libres con la voluntad de cuestionar lo que se les impone y rebelarse contra la fuerza superior del destino cruel que cambia el cauce de los eventos a su antojo.

Estos dos aspectos de la personalidad de los protagonistas del Shahnamé los vuelve reales y palpables, como personajes de la actualidad, sin ocultar sus dimensiones sobrenatura- 
les, que los conectan con lo sagrado y lo desconocido a través de funciones míticas. Así, Zahak es un prototipo de tirano y Fereydún, cualquier líder justo, cualquier salvador espiritual fácil de reconocer en un entorno actual. Los personajes del Shahnamé, a excepción de los del ciclo histórico, son seres míticos humanizados y seres humanos simbolizados en mitos, y gracias a ellos la obra es un puente entre lo mítico y lo real, siempre vigente y capaz de crear nuevos mitos y nuevas realidades.

Dirección institucional de la autora:

Instituto de Investigaciones Filológicas

Universidad Nacional Autónoma de México

Circuito Mario de la Cueva s./n.

Ciudad Universitaria

04510, Ciudad de México

\section{Bibliografía}

Aghaee, Shirzad, Nam-e kasan va ja'i-ha dar Shahnama-ye Ferdousi, Nyköping, Behrang, 1993.

Avesta, 2 vols., ed. de Yalil Dustjah, Teherán, Morvarid, 1991.

Bahar, Mehrdad, Pajuheshi dar asātire irān, Teherán, Agah, 2014.

BEIZAí, Bahram, Hezar afsan kojast?, Teherán, Roshangarán, 2011.

Benveniste, Émile, Titres et noms propres en Iran ancien, París, C.

Klincksieck, 1966.

Bondahesh, ed. de Mehrdad Bahar, Teherán, Tus, 2012.

DAvis, Dick, Epic and Sedition: A Case of Ferdoresi's Shahnamé, Odenton, Mage Publishers, 2006.

DumézIL, G., Les dieux Indo-européens, París, Presses Universitaires de France, 1952.

Eslami Nadushan, Mohammad Ali, Zendegui va Marg-e Pablevanan dar Shahnamé, Teherán, Sahami Enteshar, 2012.

Ferdousí, Abol Qasem, Shahnamé, ed. de B. E. Edvardovich, Teherán, Qoqnus, 2014.

Lincoln, Bruce, Priests, Warriors and Cattle, Berkeley-Los Ángeles, California University Press, 1981.

Meskub, Shahroj, Armaqane mur: jostari dar Shahnamé, Teherán, Ney, 2004. 
Meskub, Shahroj, Chand goftar dar farhangue irán, Teherán, Zenderud, 1992.

Mesкub, Shahroj, "Ta.amoli dar akhlagh: az avesta be Shahnamé", Irannameh, núm. 64, 1999, pp. 579-596.

Nöldeke, Theodor, Hemaseye meli-e Iran, trad. Bozorg Alavi, Teherán, Negah, 2006.

OMIDSALAR, Mahmoud, Poetics and Politics of Iran's National Epic, the Shahnameh, Nueva York, Palgrave Macmillan, 2011.

SARKARATí, Bahmán, "Bonyane asatirie hemaseye mellie iran", Revista de la Facultad de Literatura y Humanidades de la Universidad de Tabriz, núm. 125, 1979, pp. 1-61. 
